\title{
Effects of statin treatment in patients with coronary artery disease and chronic kidney disease
}

\author{
Hidehiro Kaneko $\cdot$ Junji Yajima $\cdot$ Yuji Oikawa $\cdot$ Shingo Tanaka $\cdot$ Daisuke Fukamachi $\cdot$ Shinya Suzuki $\cdot$ \\ Koichi Sagara · Takayuki Otsuka - Shunsuke Matsuno $\cdot$ Ryuichi Funada Hiroto Kano $\cdot$ Tokuhisa Uejima \\ Akira Koike $\cdot$ Kazuyuki Nagashima $\cdot$ Hajime Kirigaya $\cdot$ Hitoshi Sawada $\cdot$ Tadanori Aizawa Takeshi Yamashita
}

Received: 13 September 2012/ Accepted: 1 February 2013/Published online: 21 February 2013

(c) The Author(s) 2013. This article is published with open access at Springerlink.com

\begin{abstract}
Statins reduce cardiovascular morbidity and mortality from coronary artery disease (CAD). However, the effects of statin therapy in patients with CAD and chronic kidney disease (CKD) remain unclear. Within a single hospital-based cohort in the Shinken Database 2004-2010 comprising all patients $(n=15,227)$ who visited the Cardiovascular Institute, we followed patients with $\mathrm{CKD}$ and $\mathrm{CAD}$ after percutaneous coronary intervention (PCI). A major adverse cardiovascular and cerebrovascular event (MACCE) was defined by composite end points, including death, myocardial infarction, cerebral infarction, cerebral hemorrhage, and target lesion revascularization. A total of 391 patients were included in this study (median follow-up time $905 \pm 679$ days). Of these, 209 patients used statins. Patients with statin therapy were younger than those without. Obesity and dyslipidemia were more common, and the glomerular filtration rate (GFR) was significantly higher, in patients undergoing statin treatment. MACCE and cardiac death tended to be less common, and all-cause death was significantly less common, in patients taking statins. Multivariate analysis showed that low estimated GFR, poor left ventricular ejection fraction, and the absence of statin therapy were independent predictors for all-cause death of CKD patients after PCI. Statin therapy was associated with reduced all-cause mortality in patients with CKD and CAD after PCI.
\end{abstract}

H. Kaneko $(\bowtie) \cdot$ J. Yajima $\cdot$ Y. Oikawa $\cdot$ S. Tanaka

D. Fukamachi · S. Suzuki - K. Sagara · T. Otsuka ·

S. Matsuno - R. Funada $\cdot$ H. Kano - T. Uejima .

A. Koike $\cdot$ K. Nagashima $\cdot$ H. Kirigaya ·

H. Sawada - T. Aizawa - T. Yamashita

Department of Cardiovascular Medicine,

The Cardiovascular Institute, 3-2-19 Nishiazabu,

Minato-ku, Tokyo 106-0031, Japan

e-mail: kanekohidehiro@gmail.com; h-kaneko@cvi.or.jp
Keywords Statin - Japanese - Chronic kidney disease Coronary artery disease $\cdot$ Percutaneous coronary intervention

\section{Introduction}

Chronic kidney disease (CKD) increases the risk of cardiovascular mortality and morbidity $[1,2]$. Furthermore, patients with coronary artery disease (CAD) are believed to have more frequently impaired renal function, and reduced renal function may result in worse clinical outcomes after revascularization therapy [2-5]. Statins reduce cardiovascular morbidity and mortality from CAD as a primary [68] and secondary [9-13] preventative. In addition, aggressive statin treatment reduces future cardiovascular events, even in CKD patients [14, 15].

$\mathrm{CAD}$ is becoming more common in the elderly as the mean age of the population increases in Japan [16]. Moreover, we previously reported that cardiovascular events, including cardiac death, nonfatal myocardial infarction (MI), or readmission for heart failure, increase significantly with declining estimated glomerular filtration rate (eGFR) [17]. In Japanese patients with acute MI, early lipid-lowering treatment with statins decreases recurring cardiovascular events-in particular, congestive heart failure [18]. Intensive statin treatment appears to be more effective than standard statin doses after acute coronary syndrome [19, 20] and stable angina pectoris [21]. However, the standard statin doses used in previous studies conducted in Western countries were larger than the standard doses approved in Japan. Individuals of Asian descent are thought to be more responsive than Caucasians to therapeutic drugs, and the respective standard doses appear to provide the same benefit to Asian patients [22]. We previously reported that statin therapy initiated early after 
the diagnosis of CAD may decrease the risk of fatal events in Japanese CAD patients [23]; however, the impact of statin therapy in patients with CKD and CAD after percutaneous coronary intervention (PCI) was less well defined.

A prospective cohort study, the Shinken Database, was designed to investigate the morbidity and mortality of Japanese patients with CAD who underwent PCI. In this study, using this database we evaluated the effects of statin treatment in patients with CKD and CAD after PCI.

\section{Patients and methods}

Study patients and protocols

The Shinken Database comprises all new patients who visit the Cardiovascular Institute in Tokyo, Japan ("Shinken" is an abbreviated name in Japanese for the name of the hospital), and excludes patients with active cancer and foreign travelers. The principal aim of this hospital-based database is surveillance of the prevalence and prognosis of cardiovascular diseases in the urban areas of Japan [24]. The registry began in June 2004, and thereafter patients have continually been registered in the database on an annual basis. The data in the present study were derived from this database between June 2004 and March 2011 (Shinken Database 2004-2010), including 15,227 new patients. Those patients with CKD and CAD who underwent PCI $(n=391)$ were enrolled in this study. PCI procedures including stent selection were performed by experienced operators. The following data were obtained: age, gender, height, body weight, prior history of $\mathrm{MI}, \mathrm{PCI}$, and coronary artery bypass graft (CABG), coronary risk factors, laboratory data, types of the implanted stents (bare-metal stent and/or drug-eluting stent), and medications at primary PCI. Ultrasound cardiography was routinely performed at the time of PCI.

\section{Patient follow-up}

The health status, incidence of cardiovascular events, and mortality are maintained in the database through linking with the medical records of the hospital, and prognostic study documents are sent annually to those who discontinued hospital visits or were referred to other hospitals.

In the present data analysis, data from after April 1, 2011 were excluded. The end of the follow-up period was therefore defined by: (1) the date of death, if the date was prior to March 31, 2011; (2) the final hospital visit or the final response to our prognostic study documents prior to March 31, 2011; or (3) March 31, 2011, when the date of death, the final hospital visit, or the final response to our study documents was later than April 1, 2011.
Ethics

The ethical committee of the Cardiovascular Institute granted ethical permission for this study, and all patients provided written informed consent.

\section{Definitions}

We confirmed the deaths of study patients in the medical records of our hospital or by the information obtained from follow-up. Body mass index (BMI) was calculated at initial PCI by dividing the patient's measured weight (in kilograms) by the square of the height (in meters); obesity was defined as a BMI of $\geq 25 \mathrm{~kg} / \mathrm{m}^{2}$. GFR was calculated using the GFR equation designed for the Japanese population: GFR $=194 \times(\text { serum creatinine })^{-1.094} \times(\text { age })^{-0.287} \times$ (0.739, if female) [25]. CKD was defined as eGFR $<60 \mathrm{ml} /$ $\min / 1.73 \mathrm{~m}^{2}$. Target lesion revascularization (TLR) is defined as any repeat revascularization procedure (percutaneous or surgical) of the original target lesion site, including the stented plus edge segments (typically $5 \mathrm{~mm}$ proximal and distal to the stent). A major adverse cardiovascular and cerebrovascular event (MACCE) was defined as a composite end point including all-cause death, MI, cerebral infarction, cerebral hemorrhage, and TLR.

\section{Statistical analysis}

Categorical and consecutive data are presented as number (\%) and mean \pm standard deviation (SD), respectively. The unpaired $t$ test was used for comparison of consecutive variables between the two groups. Chi-square analysis was used to compare categorical variables. Long-term eventfree survival was estimated using Kaplan-Meier curves, and the log-rank test was used to assess the significance of differences between patients with and without statin treatment. Univariate Cox regression analysis was used to identify cofactors with significant effects on all-cause death in CKD and CAD patients after PCI. Multivariate Cox regression analysis was performed to determine the independent prognostic factors for all-cause death of CKD and CAD patients after PCI. A probability value of less than 0.05 was considered to indicate a statistically significant difference. These analyses were performed using SPSS software (SPSS, Chicago, IL, USA), version 19.0.

\section{Results}

Patients' characteristics

Of 391 patients, 209 (54\%) were taking statins. The median follow-up period was $905 \pm 679$ days. Patients 
taking statins were younger than patients without statins $(68.7 \pm 10.1$ vs $72.0 \pm 9.9$ years, $P=0.001)$. Obesity $(43.3$ $\%$ vs $28.2 \%, P=0.001)$ and dyslipidemia (73.7 \% vs 34.6 $\%, P<0.001)$ were more common in patients taking statins than in those who were not. Patients taking statins had significantly higher eGFR $(47.3 \pm 12.6$ vs $42.0 \pm 17.7 \mathrm{ml} /$ $\left.\min / 1.73 \mathrm{~m}^{2}, P=0.001\right)$. Triglyceride levels were significantly higher in the patients taking statins $(151.7 \pm 111.0$ vs $127.8 \pm 79.1 \mathrm{mg} / \mathrm{dl}, P=0.015)$. Patients taking statins more commonly used dual antiplatelet therapy (98.6\% vs $91.8 \%, P=0.001$; Table 1).

Echocardiographic findings

Ultrasound cardiography showed that the left ventricular ejection fraction (LVEF) was comparable between patients taking and not taking statins $(59.4 \% \pm 14.5 \%$ vs $58.7 \%$ $\pm 16.3 \%, P=0.688$; Table 1).
Table 1 Patients' characteristics
Data are expressed as mean \pm $\mathrm{SD}$, or counts (percentage)

ACS acute coronary syndrome, Prior MI prior history of myocardial infarction, Prior $P C I$ prior history of percutaneous coronary intervention, Prior $C A B G$ prior history of coronary artery bypass graft, $e G F R$ estimated glomerular filtration rate, $L D L$ low-density lipoprotein cholesterol, $H D L$ high-density lipoprotein cholesterol, $T G$ triglyceride, JDS Japan Diabetic Society, $H b A 1 c$ hemoglobin A1c, $L V E F$ left ventricular ejection fraction, $D A P T$ dual antiplatelet therapy, Statin HMG-CoA inhibitor, ACE-I angiotensin-converting enzyme inhibitor, $A R B$ angiotensin II receptor blocker, RAS-I reninangiotensin system inhibitor, $C C B$ calcium-channel blocker, $L M T$ left main trunk disease, $M V D$ multivessel disease, $B M S$ bare-metal stent, DES drugeluting stent

\begin{tabular}{|c|c|c|c|}
\hline & $\begin{array}{l}\text { Statin }(-) \\
(n=182)\end{array}$ & $\begin{array}{l}\text { Statin }(+) \\
(n=209)\end{array}$ & $P$ value \\
\hline Age (years) & $72.0 \pm 9.9$ & $68.7 \pm 10.1$ & 0.001 \\
\hline Male gender & $139 / 182(76.4)$ & $163 / 209(78.0)$ & 0.704 \\
\hline Obesity & $50 / 177(28.2)$ & $90 / 208(43.3)$ & 0.002 \\
\hline ACS & $65 / 182(35.7)$ & $76 / 209(36.4)$ & 0.894 \\
\hline Prior MI & 26/182 (14.3) & $32 / 209(15.3)$ & 0.776 \\
\hline Prior PCI & $16 / 182(8.8)$ & $31 / 209(14.8)$ & 0.067 \\
\hline Prior CABG & $11 / 182(6.0)$ & $13 / 209(6.2)$ & 0.942 \\
\hline Hypertension & $131 / 182(72.0)$ & $142 / 209(67.9)$ & 0.386 \\
\hline Diabetes mellitus & $67 / 182(36.8)$ & $79 / 209(37.8)$ & 0.841 \\
\hline Dyslipidemia & $63 / 182(34.6)$ & $154 / 209(73.7)$ & $<0.001$ \\
\hline Hyperuricemia & $88 / 182(48.4)$ & $76 / 209(36.4)$ & 0.017 \\
\hline Cigarette smoking & $48 / 182(26.4)$ & $59 / 209(28.2)$ & 0.681 \\
\hline Family history & $22 / 182(12.1)$ & $37 / 209(17.7)$ & 0.122 \\
\hline eGFR $\left(\mathrm{ml} / \mathrm{min} / 1.73 \mathrm{~m}^{2}\right)$ & $42.0 \pm 17.7$ & $47.3 \pm 12.6$ & 0.001 \\
\hline Total cholesterol (mg/dl) & $185.3 \pm 36.2$ & $193.0 \pm 45.9$ & 0.066 \\
\hline LDL (mg/dl) & $108.0 \pm 32.3$ & $113.0 \pm 37.5$ & 0.160 \\
\hline HDL (mg/dl) & $51.4 \pm 16.6$ & $49.4 \pm 13.3$ & 0.197 \\
\hline $\mathrm{TG}(\mathrm{mg} / \mathrm{dl})$ & $127.8 \pm 79.1$ & $151.7 \pm 111.0$ & 0.015 \\
\hline Glucose (mg/dl) (JDS) & $139.8 \pm 65.4$ & $137.6 \pm 52.7$ & 0.716 \\
\hline HbA1c $(\%)$ & $6.0 \pm 1.0$ & $6.2 \pm 1.3$ & 0.113 \\
\hline LVEF $(\%)$ & $58.7 \pm 16.3$ & $59.4 \pm 14.5$ & 0.688 \\
\hline DAPT & $167 / 182(91.8)$ & 206/209 (98.6) & 0.001 \\
\hline Anticoagulant therapy & $21 / 182(11.5)$ & 19/209 (9.1) & 0.426 \\
\hline$\beta$-Blockers & $67 / 182(36.8)$ & $80 / 209(38.3)$ & 0.766 \\
\hline ACE-Is & 25/182 (13.7) & 43/209 (20.6) & 0.075 \\
\hline ARBs & $85 / 182(46.7)$ & $92 / 209(44.0)$ & 0.595 \\
\hline RAS-I & $107 / 182(58.8)$ & $130 / 209(62.2)$ & 0.491 \\
\hline $\mathrm{CCBs}$ & $83 / 182(45.6)$ & $96 / 209$ (45.9) & 0.948 \\
\hline Vasodilators & $67 / 182(36.8)$ & $78 / 209(37.3)$ & 0.917 \\
\hline Antihyperuricemic & $42 / 182(23.1)$ & $43 / 209(20.6)$ & 0.550 \\
\hline Diuretics & $53 / 182(29.1)$ & $44 / 209(21.1)$ & 0.065 \\
\hline Aldosterone antagonist & $22 / 182(12.1)$ & $16 / 209(7.7)$ & 0.140 \\
\hline Antidiabetic & $36 / 182(19.8)$ & $52 / 209(24.9)$ & 0.228 \\
\hline Insulin & $8 / 182(4.4)$ & $7 / 209(3.3)$ & 0.591 \\
\hline LMT & $15 / 182(8.2)$ & 23/209 (11.0) & 0.358 \\
\hline MVD & $121 / 182(66.5)$ & $144 / 209(68.9)$ & 0.610 \\
\hline BMS & $61 / 182(33.5)$ & $61 / 209(29.2)$ & 0.357 \\
\hline DES & $103 / 182(56.6)$ & $146 / 209(69.9)$ & 0.007 \\
\hline
\end{tabular}


Angiographic findings

Coronary angiography showed that the prevalence of left main trunk (LMT) disease $(11.0 \%$ vs $8.2 \%, P=0.358)$ and multivessel disease (MVD) $(68.9 \%$ vs $66.5 \%, P=$ 0.610) were comparable between patients using and not using statins (Table 1).

Table 2 Clinical outcomes

\begin{tabular}{lllr}
\hline & $\begin{array}{l}\text { Statin }(-) \\
(n=182)\end{array}$ & $\begin{array}{l}\text { Statin }(+) \\
(n=209)\end{array}$ & $P$ value \\
\hline MACCE & $58 / 182(31.9)$ & $54 / 209(25.8)$ & 0.188 \\
All-cause death & $29 / 182(15.9)$ & $9 / 209(4.3)$ & $<0.001$ \\
Cardiac death & $10 / 182(5.5)$ & $3 / 209(1.4)$ & 0.026 \\
MI & $4 / 182(2.2)$ & $6 / 209(2.9)$ & 0.674 \\
TLR & $28 / 182(15.4)$ & $40 / 209(19.1)$ & 0.329 \\
\hline
\end{tabular}

Data are expressed as counts (percentage)

$M A C C E$ major adverse cardiovascular and cerebrovascular event, $M I$ myocardial infarction, TLR target lesion revascularization
Clinical outcomes

All-cause death and cardiac death occurred in 9 and 3 patients taking statins, respectively, and 29 and 10 patients who were not taking statins (Table 2). Kaplan-Meier curves and the log-rank test revealed that the frequencies of MACCE $(P=0.188)$ and cardiac death $(P=0.052)$ tended to be lower in patients using statin therapy than in those who did not, and the frequency of all-cause death was significantly lower in patients taking statins than in those who did not $(P=0.001)$. The frequencies of $\mathrm{MI}(P=$ 0.662), and TLR $(P=0.507)$ were comparable between patients using and not using statins (Fig. 1).

Predictors of death

Univariate Cox regression analysis showed that obesity, acute coronary syndrome (ACS), eGFR, glucose levels, LVEF, statins, diuretics, and aldosterone antagonists were associated with death (from all causes) in CKD patients after PCI (Table 3). Multivariate Cox regression analysis, including the significant predictors above and the marginally


Fig. 1 Kaplan-Meier curves for the major adverse cardiovascular and cerebrovascular event $(M A C C E)$-free survival rate (a), all-cause death-free survival rate (b), cardiac death-free survival rate (c),

myocardial infarction (MI)-free survival rate (d), and target lesion revascularization (TLR)-free survival rate (e) 
Table 3 Unadjusted predictors for all-cause death

\begin{tabular}{|c|c|c|c|}
\hline & $P$ value & Hazard ratio & $95 \% \mathrm{CI}$ \\
\hline Age (years) & 0.057 & 1.032 & $0.999-1.067$ \\
\hline Male gender & 0.508 & 0.784 & $0.380-1.614$ \\
\hline Obesity & 0.015 & 0.336 & $0.139-0.810$ \\
\hline ACS & 0.006 & 2.461 & $1.291-4.690$ \\
\hline Prior MI & 0.242 & 1.595 & $0.729-3.490$ \\
\hline Prior PCI & 0.688 & 1.213 & $0.473-3.115$ \\
\hline Prior CABG & 0.762 & 0.803 & $0.193-3.334$ \\
\hline Hypertension & 0.073 & 0.557 & $0.294-1.056$ \\
\hline Diabetes mellitus & 0.045 & 1.917 & $1.013-3.626$ \\
\hline Dyslipidemia & 0.072 & 0.553 & $0.290-1.053$ \\
\hline Hyperuricemia & 0.879 & 1.051 & $0.554-1.994$ \\
\hline Cigarette smoking & 0.113 & 0.515 & $0.227-1.171$ \\
\hline Family history & 0.144 & 0.415 & $0.128-1.351$ \\
\hline eGFR & $<0.001$ & 0.963 & $0.947-0.978$ \\
\hline Total cholesterol (mg/dl) & 0.209 & 0.995 & $0.986-1.003$ \\
\hline LDL (mg/dl) & 0.119 & 0.992 & $0.982-1.002$ \\
\hline HDL (mg/dl) & 0.430 & 1.008 & $0.988-1.029$ \\
\hline $\mathrm{TG}(\mathrm{mg} / \mathrm{dl})$ & 0.119 & 0.996 & $0.991-1.001$ \\
\hline Glucose (mg/dl) (JDS) & $<0.001$ & 1.008 & $1.004-1.012$ \\
\hline HbA1c (\%) & 0.216 & 1.164 & $0.915-1.480$ \\
\hline LVEF (\%) & $<0.001$ & 0.953 & $0.936-0.970$ \\
\hline DAPT & 0.847 & 1.152 & $0.274-4.851$ \\
\hline Anticoagulant therapy & 0.659 & 0.767 & $0.236-2.495$ \\
\hline Statins & 0.001 & 0.287 & $0.135-0.608$ \\
\hline$\beta$-Blockers & 0.728 & 1.122 & $0.585-2.151$ \\
\hline ACE-Is & 0.861 & 0.929 & $0.407-2.118$ \\
\hline ARBs & 0.115 & 0.568 & $0.281-1.148$ \\
\hline RAS-I & 0.127 & 0.608 & $0.321-1.152$ \\
\hline CCBs & 0.038 & 0.466 & $0.226-0.960$ \\
\hline Vasodilators & 0.550 & 0.815 & $0.416-1.594$ \\
\hline Diuretics & 0.006 & 2.461 & $1.290-4.693$ \\
\hline Aldosterone antagonist & $<0.001$ & 3.840 & $1.856-7.943$ \\
\hline Antidiabetic & 0.850 & 1.075 & $0.509-2.271$ \\
\hline Insulin & 0.688 & 0.666 & $0.091-4.858$ \\
\hline LMT & 0.462 & 1.424 & $0.555-3.656$ \\
\hline MVD & 0.275 & 1.544 & $0.707-3.370$ \\
\hline
\end{tabular}

ACS acute coronary syndrome, Prior $M I$ prior history of myocardial infarction, Prior PCI prior history of percutaneous coronary intervention, Prior $C A B G$ prior history of coronary artery bypass graft, $e G F R$ estimated glomerular filtration rate, $L D L$ low-density lipoprotein cholesterol, $H D L$ high-density lipoprotein cholesterol, $T G$ triglyceride, JDS Japan Diabetic Society, HbAlc hemoglobin A1c, $L V E F$ left ventricular ejection fraction, $D A P T$ dual antiplatelet therapy, Statin HMG-CoA inhibitor, ACE-I angiotensin-converting enzyme inhibitor, $A R B$ angiotensin II receptor blocker, $R A S-I$ renninangiotensin system inhibitor, $C C B$ calcium-channel blocker, $L M T$ left main trunk disease, $M V D$ multivessel disease, $C I$ confidence interval

significant ones $(P<0.10)$ (including age, hypertension, and dyslipidemia) in the univariate model, showed that low eGFR, poor LVEF, and the absence of statin treatment were independent predictors of death in CKD patients after PCI (Table 4).

\section{Discussion}

The present study showed that statin treatment reduced allcause mortality of Japanese CAD patients after PCI complicated with CKD. Multivariate Cox regression analysis showed that the absence of statin treatment, as well as low eGFR and poor LVEF, was an independent predictor of allcause death of CKD patients after PCI.

Statins are promising agents for CAD, as supported by a plethora of clinical evidence [7, 9, 11]. In Western countries, statins are administered to $80 \%-90 \%$ of CAD patients [26]. By contrast, in the present study CKD patients received statins after PCI in $54 \%$ of cases. Administration of statin therapy was determined by the attending physician, based on the guidelines. Although statins were prescribed for patients, they were often not taken or discontinued for different reasons. These findings should reassure physicians that the use of statin treatment is critical for patients with CAD after PCI to prevent adverse outcomes. Because underuse of statins in patients with CKD may relate to potential toxicity concerns in patients with impaired renal function, the recommendation of the National Lipid Association Statins Safety Assessment Task Force [27] indicated that CKD should not preclude the use of statins.

It was controversial that treatment with statin might prevent future cardiac events of patients with renal dysfunction [28-31]. In the 4D study, atorvastatin had no statistically significant effect on the composite primary end point of cardiovascular death, nonfatal MI, and stroke in patients with diabetes receiving hemodialysis, suggesting that the benefit of statin treatment was limited when intervention with statins was postponed until patients had reached end-stage renal disease [32]. In this study, the number of patients receiving hemodialysis was only $8.7 \%$ (34/391) and most of the study patients had mild CKD. Hence, early statin administration in CKD patients might provide clinical benefit. These findings should reassure physicians that the use of statin treatment is critical for patients with CAD after PCI in preventing adverse outcomes. There may thus be room for further improvement of clinical outcomes by increased use of statins.

To our knowledge, limited data have shown the effects of statin therapy for unselected Japanese CKD patients with CAD who underwent PCI with a broad range of lipid levels; the present study therefore newly demonstrates importance of statin treatment by revealing a significant reduction in all-cause mortality of CKD patients. However, we do not fully understand why the statin treatment 
Table 4 Adjusted determinants of all-cause death

$A C S$ acute coronary syndrome, $e G F R$ estimated glomerular filtration rate, $L V E F$ left ventricular ejection fraction Statin HMG-CoA inhibitor, $C C B$ calcium-channel blocker

\begin{tabular}{lclll}
\hline & Univariate $P$ value & $P$ value & Hazard ratio & $95 \%$ CI \\
\hline Age & 0.057 & 0.172 & 1.028 & $0.988-1.069$ \\
Obesity & 0.015 & 0.260 & 0.586 & $0.232-1.484$ \\
ACS & 0.006 & 0.889 & 0.943 & $0.413-2.150$ \\
Hypertension & 0.073 & 0.345 & 0.687 & $0.316-1.497$ \\
Diabetes mellitus & 0.045 & 0.214 & 1.672 & $0.743-3.764$ \\
Dyslipidemia & 0.072 & 0.568 & 1.268 & $0.560-2.871$ \\
eGFR & $<0.001$ & 0.011 & 0.973 & $0.952-0.994$ \\
Glucose & $<0.001$ & 0.259 & 1.003 & $0.998-1.007$ \\
LVEF & $<0.001$ & 0.005 & 0.963 & $0.939-0.989$ \\
Statin & 0.001 & 0.023 & 0.348 & $0.140-0.866$ \\
CCBs & 0.038 & 0.748 & 1.156 & $0.479-2.791$ \\
Diuretics & 0.006 & 0.653 & 0.809 & $0.322-2.035$ \\
Aldosterone antagonists & $<0.001$ & 0.441 & 1.559 & $0.504-4.826$ \\
\hline
\end{tabular}

reduced the all-cause mortality rate in patients with $\mathrm{CKD}$ and CAD who underwent PCI. Statins are known to have pleiotropic effects, including improving endothelial function [33], decreasing platelet activity [33], and attenuating inflammation [34, 35], which may contribute to the decreased mortality rate in CAD and CKD patients.

We found a discrepancy between all-cause mortality and adverse cardiac events in the present study. Previous studies reported that TLR and other cardiovascular events are reduced by statin treatment. This was not observed in the present study. The effect of statin treatment on plaque regression acts in a dose-dependent manner, which may underlie this discrepancy between the present study and previous ones conducted in Western countries. In addition, the lipid profiles of subjects in this study were almost within normal range. Because baseline levels of low-density lipoprotein cholesterol may alter the overall benefit of statins, it is possible that statins, used in doses approved for Japanese subjects, were not sufficient to reduce the restenosis rate or atherosclerotic burden during the follow-up period. Furthermore, PCI was performed in our institute using a careful stent-deployment technique with routine use of intravascular ultrasound. Although the pleiotropic effects of statins can contribute to reduced mortality, the reasons for the discrepancy between mortality and morbidity in our study are not fully explained. Further studies are required to investigate the mechanisms by which statin treatment may prevent fatal events.

\section{Study limitations}

We recognize that the present study had several limitations. First, this study reflects the experience of a single center, and the number of patients in the study was small. The statistical power may not be sufficient for negative data to be conclusive. Accordingly, more studies in a larger cohort are needed. Second, we divided patients into two groups, a statin group and a nonstatin group, irrespective of statin types and doses. Further study will be needed to clarify the appropriate types and doses of statin treatment for CAD and CKD patients. Finally, cholesterol profiles and medications were not assessed during follow-up, and some patients in the nonstatin group may have subsequently begun to take statins, while others in the statin group may have discontinued the treatment. However, this misclassification bias would have led us to underestimate the true effects of statin treatment. Despite these limitations, we believe that our findings provide valuable information to inform future treatment for patients with CKD and CAD after PCI, because the target population is representative of patients seen in daily clinical practice and the statin doses in this study were consistent with those used in clinical settings in Japan.

\section{Conclusion}

Statin treatment reduced all-cause mortality in Japanese CKD and CAD patients who underwent PCI. The absence of statin treatment, as well as poor left ventricular function and reduced renal function, was an independent predictor for all-cause death of CKD patients, suggesting a crucial role of statin treatment in long-term clinical outcomes of $\mathrm{CKD}$ and CAD patients.

Acknowledgments We thank Shiro Ueda and Nobuko Ueda of Medical Edge Co., Ltd., for assembling the Clinical Study Supporting System (CliSSS) database. We also thank Ineko Hayakawa, Hiroaki Arai, and Hiroshi Aoki for data management and system administration, and all staff in the intervention laboratory in our institute. 
Open Access This article is distributed under the terms of the Creative Commons Attribution License which permits any use, distribution, and reproduction in any medium, provided the original author(s) and the source are credited.

\section{References}

1. Levey AS, Coresh J, Balk E, Kausz AT, Levin A, Steffes MW, Hogg RJ, Perrone RD, Lau J, Eknoyan G (2003) National Kidney Foundation practice guidelines for chronic kidney disease: evaluation, classification, and stratification. Ann Intern Med 139: 137-147

2. Sarnak MJ, Levey AS, Schoolwerth AC, Coresh J, Culleton B, Hamm LL, McCullough PA, Kasiske BL, Kelepouris E, Klag MJ, Parfrey P, Pfeffer M, Raij L, Spinosa DJ, Wilson PW (2003) Kidney disease as a risk factor for development of cardiovascular disease: a statement from the American Heart Association Councils on Kidney in Cardiovascular Disease, High Blood Pressure Research, Clinical Cardiology, and Epidemiology and Prevention. Circulation 108:2154-2169

3. Tonelli M, Jose P, Curhan G, Sacks F, Braunwald E, Pfeffer M (2006) Proteinuria, impaired kidney function, and adverse outcomes in people with coronary disease: analysis of a previously conducted randomised trial. BMJ 332:1426

4. Wison S, Foo K, Cunningham J, Cooper J, Deaner A, Knight C, Ranjadayalan K, Timmis AD (2003) Renal function and risk stratification in acute coronary syndromes. Am J Cardiol 91: 1051-1054

5. Reinecke H, Trey T, Matzkies F, Fobker M, Breithardt G, Schaefer RM (2003) Grade of chronic renal failure, and acute and long-term outcome after percutaneous coronary interventions. Kidney Int 63:696-701

6. Shepherd J, Cobbe SM, Ford I, Isles CG, Lorimer AR, MacFarlane PW, McKillop JH, Packard CJ (1995) Prevention of coronary heart disease with pravastatin in men with hypercholesterolemia. West of Scotland Coronary Prevention Study Group. N Engl J Med 333:1301-1307

7. Ridker PM, Danielson E, Fonseca FA, Genest J, Gotto AM Jr, Kastelein JJ, Koenig W, Libby P, Lorenzatti AJ, MacFadyen JG, Nordestgaard BG, Shepherd J, Willerson JT, Glynn RJ (2008) Rosuvastatin to prevent vascular events in men and women with elevated C-reactive protein. N Engl J Med 359:2195-2207

8. Mills EJ, Rachlis B, Wu P, Devereaux PJ, Arora P, Perri D (2008) Primary prevention of cardiovascular mortality and events with statin treatments: a network meta-analysis involving more than 65,000 patients. J Am Coll Cardiol 52:1769-1781

9. (1994) Randomised trial of cholesterol lowering in 4444 patients with coronary heart disease: the Scandinavian Simvastatin Survival Study (4S). Lancet 344:1383-1389

10. Sacks FM, Pfeffer MA, Moye LA, Rouleau JL, Rutherford JD, Cole TG, Brown L, Warnica JW, Arnold JM, Wun CC, Davis BR, Braunwald E (1996) The effect of pravastatin on coronary events after myocardial infarction in patients with average cholesterol levels. Cholesterol and Recurrent Events Trial investigators. N Engl J Med 335:1001-1009

11. (1998) Prevention of cardiovascular events and death with pravastatin in patients with coronary heart disease and a broad range of initial cholesterol levels. The Long-Term Intervention with Pravastatin in Ischaemic Disease (LIPID) Study Group. N Engl J Med 339:1349-1357

12. Stenestrand U, Wallentin L (2001) Early statin treatment following acute myocardial infarction and 1-year survival. JAMA 285:430-436
13. Aronow HD, Topol EJ, Roe MT, Houghtaling PL, Wolski KE, Lincoff AM, Harrington RA, Califf RM, Ohman EM, Kleiman NS, Keltai M, Wilcox RG, Vahanian A, Armstrong PW, Lauer MS (2001) Effect of lipid-lowering therapy on early mortality after acute coronary syndromes: an observational study. Lancet 357:1063-1068

14. Shepherd J, Kastelein JJ, Bittner V, Deedwania P, Breazna A, Dobson S, Wilson DJ, Zuckerman A, Wenger NK (2008) Intensive lipid lowering with atorvastatin in patients with coronary heart disease and chronic kidney disease: the TNT (Treating to New Targets) study. J Am Coll Cardiol 51:1448-1454

15. Ridker PM, MacFadyen J, Cressman M, Glynn RJ (2010) Efficacy of rosuvastatin among men and women with moderate chronic kidney disease and elevated high-sensitivity C-reactive protein: a secondary analysis from the JUPITER (Justification for the Use of Statins in Prevention-an Intervention Trial Evaluating Rosuvastatin) trial. J Am Coll Cardiol 55:1266-1273

16. Kubo M, Kiyohara Y, Kato I, Tanizaki Y, Arima H, Tanaka K, Nakamura H, Okubo K, Iida M (2003) Trends in the incidence, mortality, and survival rate of cardiovascular disease in a Japanese community: the Hisayama study. Stroke 34:2349-2354

17. Nakamura M, Yamashita T, Yajima J, Oikawa Y, Ogasawara K, Kirigaya H, Sagara K, Koike A, Sawada H, Aizawa T (2009) Impact of reduced renal function on prognosis in Japanese patients with coronary artery disease: a prospective cohort of Shinken Database 2007. Hypertens Res 32:920-926

18. Sakamoto T, Kojima S, Ogawa H, Shimomura H, Kimura K, Ogata Y, Sakaino N, Kitagawa A (2006) Effects of early statin treatment on symptomatic heart failure and ischemic events after acute myocardial infarction in Japanese. Am J Cardiol 97: $1165-1171$

19. Cannon CP, Braunwald E, McCabe CH, Rader DJ, Rouleau JL, Belder R, Joyal SV, Hill KA, Pfeffer MA, Skene AM (2004) Intensive versus moderate lipid lowering with statins after acute coronary syndromes. N Engl J Med 350:1495-1504

20. Murphy SA, Cannon CP, Wiviott SD, de Lemos JA, Blazing MA, McCabe CH, Califf RM, Braunwald E (2007) Effect of intensive lipid-lowering therapy on mortality after acute coronary syndrome (a patient-level analysis of the Aggrastat to Zocor and Pravastatin or Atorvastatin Evaluation and Infection TherapyThrombolysis in Myocardial Infarction 22 trials). Am J Cardiol 100:1047-1051

21. LaRosa JC, Grundy SM, Waters DD, Shear C, Barter P, Fruchart JC, Gotto AM, Greten H, Kastelein JJ, Shepherd J, Wenger NK (2005) Intensive lipid lowering with atorvastatin in patients with stable coronary disease. N Engl J Med 352:1425-1435

22. Liao JK (2007) Safety and efficacy of statins in Asians. Am J Cardiol 99:410-414

23. Nakamura M, Yamashita T, Yajima J, Oikawa Y, Ogasawara K, Sagara K, Koike A, Kirigaya H, Nagashima K, Otsuka T, Uejima T, Funada R, Matsuno S, Suzuki S, Sawada H, Aizawa T (2011) Impact of early statin initiation on secondary prevention in Japanese patients with coronary artery disease. J Cardiol 57:172-180

24. Suzuki S, Yamashita T, Ohtsuka T, Sagara K, Uejima T, Oikawa Y, Yajima J, Koike A, Nagashima K, Kirigaya H, Ogasawara K, Sawada H, Aizawa T (2008) Prevalence and prognosis of patients with atrial fibrillation in Japan: a prospective cohort of Shinken Database 2004. Circ J 72:914-920

25. Matsuo S, Imai E, Horio M, Yasuda Y, Tomita K, Nitta K, Yamagata K, Tomino Y, Yokoyama H, Hishida A (2009) Revised equations for estimated GFR from serum creatinine in Japan. Am J Kidney Dis 53:982-992

26. Borden WB, Redberg RF, Mushlin AI, Dai D, Kaltenbach LA, Spertus JA (2011) Patterns and intensity of medical therapy in patients undergoing percutaneous coronary intervention. JAMA 305:1882-1889 
27. Kasiske BL, Wanner C, O'Neill WC (2006) An assessment of statin safety by nephrologists. Am J Cardiol 97:82C-85C

28. Seliger SL, Weiss NS, Gillen DL, Kestenbaum B, Ball A, Sherrard DJ, Stehman-Breen CO (2002) HMG-CoA reductase inhibitors are associated with reduced mortality in ESRD patients. Kidney Int 61:297-304

29. Cosio FG, Pesavento TE, Pelletier RP, Henry M, Ferguson RM, Kim S, Lemeshow S (2002) Patient survival after renal transplantation III: the effects of statins. Am J Kidney Dis 40:638-643

30. Holdaas H, Fellstrom B, Jardine AG, Holme I, Nyberg G, Fauchald P, Gronhagen-Riska C, Madsen S, Neumayer HH, Cole E, Maes B, Ambuhl P, Olsson AG, Hartmann A, Solbu DO, Pedersen TR (2003) Effect of fluvastatin on cardiac outcomes in renal transplant recipients: a multicentre, randomised, placebocontrolled trial. Lancet 361:2024-2031

31. Tonelli M, Isles C, Curhan GC, Tonkin A, Pfeffer MA, Shepherd J, Sacks FM, Furberg C, Cobbe SM, Simes J, Craven T, West M (2004) Effect of pravastatin on cardiovascular events in people with chronic kidney disease. Circulation 110:1557-1563
32. Wanner C, Krane V, Marz W, Olschewski M, Mann JF, Ruf G, Ritz E (2005) Atorvastatin in patients with type 2 diabetes mellitus undergoing hemodialysis. N Engl J Med 353:238-248

33. Dupuis J, Tardif JC, Cernacek P, Theroux P (1999) Cholesterol reduction rapidly improves endothelial function after acute coronary syndromes. The RECIFE (reduction of cholesterol in ischemia and function of the endothelium) trial. Circulation 99:3227-3233

34. Ridker PM, Rifai N, Pfeffer MA, Sacks F, Braunwald E (1999) Long-term effects of pravastatin on plasma concentration of C-reactive protein. The Cholesterol and Recurrent Events (CARE) Investigators. Circulation 100:230-235

35. Ridker PM, Danielson E, Fonseca FA, Genest J, Gotto AM Jr, Kastelein JJ, Koenig W, Libby P, Lorenzatti AJ, Macfadyen JG, Nordestgaard BG, Shepherd J, Willerson JT, Glynn RJ (2009) Reduction in C-reactive protein and LDL cholesterol and cardiovascular event rates after initiation of rosuvastatin: a prospective study of the JUPITER trial. Lancet 373:1175-1182 